\title{
OCEAN AS HERITAGE: ON TAMIL POETRY AND IDENTITY, TRANSNATIONAL POLITICS, AND THE RECOGNITION OF GENOCIDE. AN INTERVIEW WITH CHERAN
}

\author{
Isabel Alonso-Breto \& Cheran Rudhramoorthy \\ University of Barcelona \& University of Windsor, Ontario (Canada)
}

ISABEL: Cheran, first of all thank you for agreeing to participate in this interview when I am aware that you are such a busy poet and academic. It is my intention to broach a variety of issues. To begin with, I would like to ask you, very generally, about your relation with poetry, more specifically when and where poetry comes to you.

Cheran: It's a very fine question. Your question is metaphorical, and I love metaphors. However, today for a change, let me take it literally, at least to start with. Poetry doesn't come to me. It lives with and within me. There are instances when I get deeply affected by images, words and wounds outside of me and by other events. As a poet, my poetic senses and my poetic antennae are always on alert, so there is no separation between poetry and life for me. That said, I can mention different ways in which poetry can arise within me. Sometimes it emerges just like a word: I get inspired by a word and that word can create the whole poem. If I take a word and throw it in the air and I follow it, it writes a poem. Some other times there is just a simple sound, such as when, in the early morning, you hear the chirping of an unknown bird outside. Yet another possible inspiration is some kind of image, for example a burning book that crosses the oceans and reaches you. In a similar way, it could be an incident, something I witness or even stories I hear. These are some of the forms in which most frequently poetry emerges in me. There are other ways too: some of my poems came to me in my dream. But I need to get up right away because otherwise they would disappear. So, if you ask me, this is the technical way of describing how poetry comes to me, and anyone who reads my poetry, either in Tamil or in translation, will discover such elements of shock or surprise, which are always there as part of it. Actually this list is not exhaustive, since there are all kinds of possible ways. That is why I always say that writing a few poems is easy, any person can write at least a few lines of good poetry, because there is a universal human attachment to beauty and to language, but being a poet, living as a poet twenty four hours seven days a week, is totally different.

DOI: https://doi.org/10.25145/j.recaesin.2021.82.15

Revista Canaria de Estudios Ingleses, 82; April 2021, pp. 201-212; ISSN: e-2530-8335 
ISABEL: You have said somewhere that you can only write poetry in Tamil, whereas as an academic and in other genres you have written extensively in English. Could you tell us something about this, about your relationship with the two languages?

Cheran: Perhaps you remember translating "Ask," one of the poems included in my anthology A Second Sunrise. In this poem there is a line where I talk about what I call "the loneliness of language". You need to imagine that I have been living for years in places where I could not speak Tamil, where I had to speak mainly in English, because there was no real possibility to talk and communicate in Tamil, but I kept writing and dreaming in Tamil: that's what I mean by the loneliness of language. Once I decided that Toronto is going to be the place I'm going to live in, even if there is a large Tamil community here with whom I can speak the language, I feel that to continue writing my poems in Tamil is the best way for me to keep organically linked to my heritage, which was largely defined by the Tamil language. I can write all kinds of texts in English but will write poetry only in Tamil in order to keep a more intimate connection to that language. Also, as you know, poetry as the linguistic expression hovers above all the other forms of writing. For poetry you need to have complete mastery of the language. Also, by way of writing in Tamil, I maintain one of the strongest aspects of our identity and culture, because the Tamil identity is largely based on a linguistic identity. In other words, Tamil does not correspond with the name of a territory or a land, even though the struggle for and aspiration to gain a fully autonomous land or territory is very much alive. Wherever Tamil is spoken by large numbers of people, the place then becomes part of a "Tamil speaking world of goodness." I keep a very strong connection to my heritage through my poetry.

My approach to the concept and practice of heritage is different. The traditional approach to heritage and culture is to assume that there are intrinsic and immutable values to culture and heritage. We expect that culture and heritage will not change and that it should not change. I would view this as a static model of heritage. This approach is not really helpful. For example, we cannot simply say that there is only one way to be a Tamil or to belong to Tamil heritage. Tamils have multiple locations, multiple ways and belonging. However, what unites us is solidarity across nations, cultures, oceans and territory. We must not forget that we are talking about an oppressed people and a community which suffered genocide, and writing poetry in Tamil is not only an act of resistance but my contribution to my language and to my heritage and to the cultural dimensions of being Tamil in multiple ways.

ISABEL: And how does English intervene in the equation?

Cheran: I'm very conscious that my poetry must be available through translations to all the people who speak different languages. I am multilingual but English becomes an important vehicle for me in that context because of 
colonialism and post-coloniality. In a way, I can be categorized as a rooted cosmopolitan. My rootedness in the larger idea of cosmopolitanism comes through my language. I am very comfortable writing in English but one of the difficulties and why I insist on writing poetry in Tamil is that my mastery over Tamil is much deeper than my mastery in English. I can write plays and I can write non-fiction and academic papers and essays in English, but regarding poetry, to have mastery you need an extraordinary ability and having grown with the language in your formative years. Although I started learning and reciting poetry in English from grade six, still I am reluctant to say I know poetry in englishes. Yes, there are several englishes. On the other hand, I have memorized, studied, and am always at home in Tamil classical and modern poetry.

ISABEL: I am very interested in your craft as a poet, in the technical aspects. How do you elaborate on a poem? Do you write different versions until you feel satisfied? When do you know that a poem is finished?

Cheran: Elaboration takes place in my mind. I do not type my poems. I write them in beautiful notebooks, journals and on other assorted but lovely papers. I am still a sucker for fine stationary. After writing them in longhand, I wait for a few days, weeks, months and sometimes years. Then I will type them up one by one. In that process, I will edit, add, cut, chop, mutilate, etc. But there were instances when I could write a poem in one go. I do not think that my poems are a finished product. As I say in one of my poems titled "I cannot finish off this poem," the poem continues. It never ends. Here is the poem:

This poem cannot be finished off writing, this song not ended, thirst not quenched.

Every memory refuses to be effaced, every plot declines to produce, every face is reluctant to endure.

A dream unwilling to dissolve, lingers forever-although

I do not know if

$\mathrm{I}$ am in the dream or out.

Wandering and transience

spread endless, dazzling rays.

What else can I send, to feed everyone the sweetness of unbitter solitude, besides this poem?

(Translated from Tamil by Geetha Sukumaran) 
ISABEL: Regarding your topics, have you ever forced yourself into writing about something, because you felt it was necessary? Have you ever, shall we say, written against yourself?

Cheran: Yes. This is what I prefer to refer to as applied poetry or using your craft and poetic imagination to do other things. For example, I have written dozens of songs to music at the request of my friends who are composers. There is a certain degree of compromise, but I really loved the end product. Similarly, I have written eulogies, felicitations, greetings, and introductions to books in poetry. It is a different kind of poetry. There are more than a hundred protest slogans, poetic lines I wrote to be used as traditional agit-prop variety. I also wrote short verses -love letters- for my friends, so they could send them to their would-be or not would-bes. It was a good experience. Though I would not consider them as writing against myself.

IsABEL: How does a poet like you rid himself of the terrible memories of war? Is poetry a form of exorcism?

Cheran: I do not think so. Writing war or war poetry is different, I think. Celebration of poppy and military heroism and sacrifice is something I do not want to compare with writing genocide. Combat trauma is not what we have gone through. What we have gone through and are still going through is a trauma of genocide and this will not end with my generation. A few weeks ago, I had an opportunity to discuss, recite and exchange poetry with a group of Tamil women who were tortured, sexually assaulted, and had some of their family members killed by the Sri Lankan security forces in 2009. They write poetry as part of their resistance and renewal. Some of the poems have opened up venues, words and images that can capture the "un-grabbable" in the context of genocide. Their poetic work heals them. I am not sure whether I can convincingly say that about my poetry. However, I can admit that writing poetry after genocide, controls my anger.

IsABEL: Let's talk about Tamil culture or as you would say cultures, of which your oeuvre is part. I know Tamil is a language spoken by more than 77 million people, and thus it is among the twenty most spoken world languages. According to you, what is the role of Tamil culture in the world?

Cheran: Tamil is one of the very few classical languages that is still in use. It is an ancient language, with a very long literary tradition: its rich body of literature and poetry dates back to BCE 500 if not earlier. Tamil has evolved without being dependant on any other language or as an offshoot of another language. And interestingly, many classical languages are now gone, in the sense that they are classical, and no one speaks them anymore in their daily life. But in the case of Tamil, as you have correctly said, there are more than 77 million people who speak it at present. Amazingly, a contemporary speaker of Tamil can read and understand at least some parts of the classical literary texts that exist in the language, even if they were written several thousand years ago. Some words that were used all those years ago are still 
used in the common everyday language in Tamil and Malayalam. Then Tamil is simultaneously a classical as well as a contemporary language. But you never see Tamil in the list of classical languages and literatures that are being taught in Euro-American universities, including my university in Canada.

IsABEL: So, the strength of Tamil culture lies in its rich past?

Cheran: The past is important to a great extent, but not only that. I always tell Tamil activists and the people who valorise Tamil culture and Tamil heritage that, instead of making a case for Tamil identity being solely based on this antiquity, we have to frame the question more broadly, that is: How and what have the Tamil language and Tamils contributed to world culture, to enrich the entire human civilization? What I mean is that we cannot, in the name of heritage and of culture, allow the communities to wallow in archaic moments of ancient glory or practice, for instance, the self-immolation of wives in the husband's funeral pyre or preventing women from crossing the oceans. Or, in the name of heritage and culture we cannot allow patriarchy to dominate every aspect of a woman's life. So, in the name of keeping the past alive you cannot say, this is our culture and heritage, and it is the best in the world, and we are a superior "race." In the case of Tamil, because there is an extremely politicized situation for the language in India, Sri Lanka and some other parts of the world, there is a tendency to go back repeatedly and frustratingly to these glorious past moments of Tamil culture with a sense of nostalgia for a lost empire, recalling powerful military expeditions. This keeps happening, but when I look at it, I say, No, these are not the creative and healthy threads of heritage and culture I would delineate from our history and heritage. There are other powerful threads and episodes we can learn and articulate.

IsABEL: Thus, I understand that you would rather identify with a more contemporary approach to Tamilness.

Cheran: That's right in a sense: my role in Tamil culture and heritage would be that of a progressive contribution, both as a poet and scholar. In Canada, we are just about to establish a Chair in Tamil studies at the University of Toronto. To contribute to this purpose, I have delivered lectures and talks in hundreds of meetings, seminars and fundraising events. In each of those I am emphasizing my ideas and asking some pertinent questions: What is Tamil heritage? What is this culture we are talking about? Can we please stop using the past glory as opium and move forward? My argument is: first of all, the heritage is a claim making. And if we are trying to articulate a kind of heritage that is "unique" or that has made a significant contribution to humanity at large, we have to clearly express what it is. In response to my questions, I have organized a list of various aspects from a critical heritage studies perspective for Tamils to think about. 
ISABEL: Would you elaborate on the most important ones?

Cheran: The first and most important aspect is to think about Tamils and Tamilness not as a singularity. There are various and multifaceted Tamil communities that inhabit several parts of the world. Being Tamil is a transnational reality and identity.

Secondly, we have a very ancient and rich poetic tradition, called Sangam poetry, and the concept of Thinai that emerged from a critical analysis of this poetry. The concept of Thinai is simultaneously a literary, theoretical and critical method and an eco-poetic convention that helps us in framing and explaining multitude of Tamil identities and heritages. There are no parallels to Thinai convention in other civilizations. Mikhail Bakhtin's Chronotopes can be considered but the Thinai is denser and multi-faceted. I have written extensively on this in English and Tamil.

The corpus of Sangam poems collected in eighteen anthologies, as you can see in the translations of A.K. Ramanujan, George Hart, A. Dakshanmurthy and several others, constitute an excellent creative contribution to humanity. We are talking here of a very old tradition that is secular in nature. Some of the values expressed in that poetry are relevant and important even now. For example, the poem which reads: "Every country is my country / every human is my kin" embodies the idea of cosmopolitanism that we envision now. In this way, cosmopolitanism, in the sense of how Appiah discusses it, was articulated and celebrated more than two millenia ago as a value and praxis. The poem says that, to someone who speaks the Tamil language, territory and land should be secondary, while what is important is the contours of feeling (pulaneri vazakku), the landscape and how you create it, how you create your own landscape in a metaphorical sense. So it is very interesting, as it takes away the idea of identity as something bound to land and territory. The idea of a human community bound, instead, to language and imagination and moods, moments, music, flora and fauna and landscapes is a different way of talking about identity and belonging.

Thirdly, the ocean. The Sea. Tamil identity cannot be studied or situated without the precolonial ancient maritime trade, voyages, seafaring, imperial military expeditions, the Coolie and indenture, refugees and the deep connection to the Indian Ocean. Indian Ocean imageries cannot be fully grasped without Tamils. In the colonial times, thousands of Tamils were traded off, sent as indentured labourers and "Coolies" -the word Coolie itself is Tamil-, then as refugees in the post-colonial period. Coolie Tamil and Refugee Tamil cannot be erased out in the discussion of Tamil identities. A significant number of Tamil poems are about oceans. As Derek Walcott says, for us, the sea is history too. But it is also an indelible part of our identity and imagination.

ISABEL: It is remarkable that such a contemporary take on identity should have been outlined so long ago. 
Cheran: Indeed. And another relevant aspect is that Tamil has always been part of a secular identity and heritage, that is, it has never been part of any singular religion. In fact, all languages originate and prefer a secular mood and mode, but in the course of time most of the languages, whether they are classical or modern, become predominantly attached to one particular religion. You see, Latin is attached to Christianity, Sanskrit to Hinduism, Persian and Arabic to Islam, and so on. But if we take Tamil, Hinduism, Saivism, Buddhism, Jainism, Christianity, Aseevakam (Ajivika), Vaishnavam (Vaishnavite) or Islam, all those religions have been part of Tamil language and identity. In that sense it has a long history of being secular and actually going beyond the common understanding of 'secular/secularism'.

IsabeL: So there is no particular connection between Tamil and Hinduism?

Cheran: The Tamil civilization and heritage have always been multicultural and multi-religious.

There is no exclusive connection between Tamil and the arbitrary colonial aggregation of hundreds of faiths as "Hinduism." Sadly, it does not prevent sections of the Tamils from claiming and articulating the contested "TamilHindu" coupling for political reasons in Sri Lanka and India.

ISABEL: What kind of relationships are established among Indian Tamils, Sri Lankan Tamils, Malaysian Tamils and, in short, Tamils hailing from different places? Because while they share a common language, their histories differ in wide ways. How do these communities come together, especially in diasporic locations?

Cheran: We do not use the term Indian Tamils. The term we use, coined by that community itself, is "Malaiyaka Thamilar" -the Tamils of the Hill country. This is what I call being a Tamil in multiple ways. It means that in the contemporary world, as I mentioned above, Tamil is a transnational identity. We can no longer confine our deliberations on Tamil identities as rooted in a single territory, be it India, Sri Lanka, Canada, Singapore, South Africa or Malaysia. There are several Tamil communities in each of these places, and one major aspect that links all of them is language, but there are also variations in the language, and different dialects. The Tamil spoken in Batticaloa is different from the Tamil spoken in Jaffna, and so on. In a similar way, the Tamil heard in those places is not the variety heard in Singapore. Even in Tamil Nadu, there are different accents in Northern and Southern Tamil Nadu. But Tamil has diglossia: when you switch from the written to the colloquial, there are differences. Yet written, formal Tamil is common to all those spoken variations all over the world.

In connection with this, we need to keep in mind that we cannot generalize talking about a common identity: there are commonalities but there are different ways of being Tamil. The identity of Tamils who left Sri Lanka as refugees is much more political than that of those Tamils who left for the Silicon Valley to work as a part of voluntary migration. Their experience 
and their context are different, thus their identity, while Tamil, has different dimensions. Anthropologist Valentine E. Daniel wrote about Being a Person the Tamil Way, but I choose to write, instead, "Being a Tamil, multiple ways." For example, let us look at the second or third generation Tamils in the diaspora. They identify very strongly as Tamils in a political sense, but most of them do not speak the language or their Tamil vocabulary is limited. And I do not think it is appropriate to tell them: Listen, you don't speak the language, so you are not Tamil.

ISABEL: Do Tamils worldwide have a common political agenda?

Cheran: I think there is a political agenda, or rather, there are all kinds of groups trying to come up with a common agenda, but there are no cohesive practical plans. In November, this year, during the lockdown, one of the largest Tamil gatherings, called Rise Tamil was held online. It was a virtual congregation of the top Tamil businessmen, women, professionals from all sectors, Tamil scientists from all over the world, politicians, writers and artists. There were more than five hundred of them; they met for three days and worked out an economic, cultural and social agenda for the Tamil speaking world. The reason why this common agenda is needed is that whether Tamils live in Sri Lanka, India, or elsewhere, there is this uneasy sense of being treated as "second class" citizens everywhere they live when it comes to the rights of the language and full articulation of Tamil identity.

ISABEL: Is this the case also in India?

Cheran: Yes, also in India, because ever since the new but strong Hindu nationalist government came into power, they are trying to systematically undermine Tamil and impose Sanskrit and Hindi. They know the demands of the people in Tamil Nadu and know that it has always been in the forefront of opposing compulsory Hindi. Further, in the past six years there have been lots of agitations against the imposition of Hindi in Tamil Nadu and Southern Indian states.

A few months ago, a member of the Indian Parliament from Tamil Nadu, a fellow Tamil poet and a friend of mine, Kanimozhi Karunanidhi, arrived at the Chennai airport in Tamil Nadu. The military official at the airport asked her if "she was an Indian" when Kanimozhi asked her to speak in English or Tamil as she did not know Hindi. This conflating of Hindi with Indian as implied by the military official at the airport was probably a routine occurrence. In another incident a few weeks prior to that, a top Indian government officer excluded non-Hindi speaking people from a central government training programme. I am afraid these are not isolated incidents. There is a trend that has intensified since 2014 when the Bharatiya Janata Party (BJP) formed the government at the Centre. The current government's project is to make "Hindi-Hindu-India" a political, social and cultural reality. 
ISABEL: In which part of the world do you think Tamil culture is in a better state of health? Could it be India, in spite of the situation? Or rather Canada, where among other things, as you have mentioned, a Chair for Tamil Studies is in the process of being created at the University of Toronto, and where Tamil culture seems to be thriving?

Cheran: I think the first generation of Tamils in diaspora are still a very large part of the population. For instance, in the Canadian context, there are some 300,000 Canadian Tamils, and a sizeable number of this population belongs to the first generation. So you can imagine that the second generation are going to have a history of their own in the next thirty or forty years. When the first generation leaves the earth, there must be a completely different Tamil system which has been set up, and which enables the possibility, for instance, to study Tamil at university level, and in schools. At the moment, a Tamil community centre is being built in Toronto with the support of the provincial and federal governments. So that infrastructure is going to be there, and then the community is putting the emphasis on teaching and learning Tamil as a heritage language. At the moment, in Canada, you can learn Tamil at school until grade eleven, and then you can use the mark to go to university. Therefore, lots of students, say around 10,000 of them, will study Tamil, because it improves their prospects to access their chosen universities. And there are all kinds of other systems which are being planned. It is the same in the UK and in other places with the teaching of Tamil. Thus, even if at present there can be some intergenerational tension in terms of using the language, I am confident that Tamil as a heritage language, as a political identity, and as a kind of influential diasporic community, is going to stay. In fact, they are becoming more and more conspicuous in terms of political power: There is a Tamil Member of Parliament in the Canadian federal government already, and several representatives in the provincial government of Ontario. And more are coming. So down the road the community will thrive. I can tell you one similar example: the Sikh community, one of the oldest in Canada, for a long time lacked any kind of proper representation in the government, while now there are five ministers of Punjabi origin in the Cabinet. Our Minister of Defence is a Sikh Canadian, as well as the Minister of Infrastructure: they are Sikh and Canadian, and they identify as both, Canadian and Punjabi. For Tamils, there are still challenges ahead.

ISABEL: You are suggesting that the prospects are similar for the Tamil-Canadian community.

Cheran: Exactly. This is what we call transnational politics. It is no longer immigrant politics. In a way, the politics of Catalonian people is also the politics in Canada. During the Israeli elections Israeli political parties used to charter flights from Toronto and Montreal to Israel for Israeli Canadians with dual citizenship, who can vote. Presidential elections in Croatia, at times can be decided by the diasporic vote. There are several examples of transnational politics here. The politics which are taking place 
in, say, Palestine, are also the politics of Toronto and Ottawa. The politics of Punjab and India are very much echoed here. For instance, not long ago, there was a huge demonstration here in Toronto in support of a farmers' protest in India. So, it is not a matter of immigrants bringing their own political culture to the diaspora, but of transnational politics being in place all around. The Canadian Prime Minister issued a statement supporting the farmer protests in India. And the Indian government was not pleased; they said the Canadian government didn't have the right to interfere. But the Canadian politicians can argue that there are more than 500,000 Punjabi Sikh Canadians in this country (a conservative estimate for sure), and they are loyal to us and they are loyal to their Sikh identity as well. We cannot simply ask them to dump their Sikh identity.

IsABEL: Definitely. Anyway, moving away from the fascinating matter of diaspora and transnational politics, which at present is such an important part of Indian Ocean imaginaries, I would now like to ask you about a poignant and deeply painful subject. Many scholars and intellectuals have qualified as genocide what occurred in the Spring of 2009 in the north of Sri Lanka, when the Sri Lankan government finally emerged as victor of a 26 -year long conflict. You count yourself among them, actually you used that word earlier on in some of your answers. My next question is whether there has been any advancement in the recognition of genocide by international organizations.

Cheran: I would like to respond to your question as a journalist who reported/ wrote about more than a hundred "genocidal massacres" in Sri Lanka, an academic who teaches a course on genocide, and as a poet who witnessed a structural genocide in Sri Lanka for twenty years. There has been a lot of activism surrounding the claim of genocide and the attempts at making the Sri Lankan government accountable for what happened in the last phase of the war. Genocide is a complicated case to establish because it has been politicized by nation-states and their international judicial institutions. For a community like Tamils, Kurdish, Palestinians, Baloch and several hundred other communities that have no "global/international" representation, it would be a very difficult task to make a case, mainly because the entire "international system" is in favour of states.

Lots of initiatives have been taken, and many efforts have been made at the level of international law in order to, again, convince the UN and other institutions to bring the Sri Lankan government to accountability. But, in order to raise awareness in various parts of the world that what happened in 2009 was genocide, we need to make them realise that it was genocide without witnesses. Thus, a big effort is being made in documenting these atrocities and creating online archives which make the case of genocide very solid. This is also an important project that challenges dominant international approaches to pre- and post-war Sri Lanka. However, the UN has sufficient evidence to call it genocide. The report of the UN Secretary General's Panel of Experts (POE) on accountability in Sri Lanka (2011), 
and the report of the Secretary-General's Internal Review Panel on United Nations Action in Sri Lanka (2012) have sufficient information, evidence and testimonies on war crimes and crimes against humanity. Although these reports did not explicitly use the term genocide, it would be clear for anyone who reads the report that genocide was committed.

There has been limited support for this, and yet the government of Ontario has declared it was genocide, and also some of the Canadian Members of Parliament and politicians have done so. A motion to declare a Tamil genocide education week in Ontario is being debated. Thus, even if the Canadian government itself has not yet recognized the episode as genocide, there is certain progress at provincial levels. And a similar thing is occurring in the UK, where some parties and organizations are calling it genocide, and also in Australia and in Norway. So you can see that in various places where the diaspora is active the demand is gaining track, and that is going to go on for a very long time. And even though the UN is complicit with what occurred, there are a couple of relevant UN resolutions -which the Sri Lankan government has chosen to ignore. President Barak Obama in his book says that the UN failed Tamils in Sri Lanka. Tamil genocide, the first genocide of the 21st century, took place while he was the US president. His government was, like the UN, complicit in the genocide. Many powerful countries were either complicit or kept mum. That is part of the reason why it will be a difficult path for them to turn around and say, yes, that was a genocide.

ISABEL: The war officially ended in 2009 . Would you like to tell us about the situation of Tamil communities in Sri Lanka in the last decade? When the war ended, besides thousands of Tamils living in diaspora, mostly in Canada as is your case, there were thousands of IDPs, Tamil people who, having been forced to abandon their homes, lived in makeshift refugee camps. What has occurred since then? Has the situation been normalised?

Cheran: The current government has militarized most of its governance. Every major ministry and Department is under the military, so much so that the Sri Lankan military is now running the country. Even the fight against Coronavirus is militarized, and the curfews and transport restrictions are organized and controlled by the military. Literally everything is controlled by them. So, what has been going on in the last ten years is a process of increasing militarization, not only in the northern and eastern areas where the Tamils live in large numbers, but now other parts of the country have come under great presence of the army in all spheres of life.

The military has an enormous amount of autonomy. They can do anything without hardly any restrictions, and this is so because the president himself was a military man, and all the important positions of power are occupied by members of the army. Even a commission of archaeology and heritage that has been created in order to peruse and study the Buddhist history and heritage in the eastern part of Sri Lanka has military officers leading it together with Buddhist monks 
Besides militarization, the second aspect that has been going on, which has been terrible for Tamils, is the Sinhala Buddhist colonization of lands which belonged to them. The government is building Buddhist temples all over the north and eastern parts, taking over the lands of the people and settling hundreds of Sinhala people in those areas. Obviously the aim is to change the demographical profile of these areas.

ISABEL: Wasn't this type of policies put in place already before the war?

Cheran: Yes, they started doing this already in 1948, but then they couldn't get results as fast as they can now. After the end of the war, they were able to do it at full speed, like a bulldozer, because there was no resistance to these efforts. So, they are taking over everything. Together with militarization and colonization, they are taking over the lands and territories belonging to the Tamils in various parts of the north and east, and not giving them back, encroaching on what we call the "military cantonments". And a fourth fact is that to do every single thing in the north and east, you need to get permission from the military, which is everywhere. If you need to get out of your home because of Coronavirus, you need permission, not from a health officer, but from the military.

The combination of militarization and Sinhala Buddhist colonization turns out to be an extremely oppressive system, not only for Tamils but for the Muslims too. Here is an example: they are forcibly cremating every single body suspected of having died from Coronavirus. And of course, the Muslim, Christian and sections of the Tamil communities are extremely upset about this practice. Sometimes the authorities will just do this without the relatives' permission. And, as one could imagine, this is creating great discomfort, because, as the UN says, the victims' rights should always be respected, yet the government does not do so. This is a very systematic way of antagonizing the minorities now. Targeting Muslim communities has been going on for the past ten years.

ISABEL: So not only Tamils but also other minority groups are affected by that kind of policies.

Cheran: Exactly. In the same way as white supremacists gained ground with Donald Trump in the US, extreme Sinhala Buddhist racist monks, with an extreme idea of Sinhala Buddhist supremacy, have gained ground in Sri Lanka. Their ideology is openly being articulated by the government, by the President, by very powerful social movements. At the moment, the situation is very dangerous. I don't know how it is going to play out in the future.

IsABEL: Let me thank you again, Cheran, for sharing this wealth of information. 